\title{
Performativity, propriety and productivity: The unintended consequences of investing in the Early Years
}

\begin{abstract}
This paper examines how notions of childhood development are represented in Investing in the Early Years - A National Early Childhood Development Strategy (Council of Australian Governments, 2009). The paper suggests that discourses of healthy childhood development as represented in this document produce definitions of 'proper' child development and thus, place certain children and families outside this idea. Proper development is addressed through understandings of responsibilisation resulting in the categorisation of 'at risk' groups unable to adhere to responsibilisation standards. The recognition of 'at risk' or 'improper' groups, and notions of productivity, are addressed through understandings of performativity while highlighting consequences for children and families.
\end{abstract}




\section{Performativity, propriety and productivity: The unintended consequences of investing in the Early Years}

\section{Early Childhood Development Investment and Outcomes}

Early childhood education and care (ECEC) is currently burgeoning as a reform agenda in Australia. Such reform has been prompted by research from authors such as Heckman (2006), who have linked future economic prosperity with investment in the early years. This policy reform and investment also brings with it the inference that children and families must meet certain expectations and be encouraged to perform as "proper" citizens in order that the results from such economic investment are realised. The idea of "proper citizenry" is produced as a consequence of particular discourses that work to inform the community as to whether children and families both contribute to and adhere to ideas of propriety and thus, whether they are worthy of such investment. These discourses of propriety tend to focus notions of citizenry around the idea that children must develop properly in order to be included in particular categories of successful performance as citizens.

The authors of this paper explore these ideas by undertaking a discourse analysis of the document Investing in the Early Years - A National Early Childhood Development Strategy (Council of Australian Governments [COAG], 2009). While the authors acknowledge that this document was introduced in 2009, it is still influencing policy today. The document is the latest policy document relating to the early years from COAG and it is expected to shape outcomes for children and families to 2020. By examining the discourses in this Strategy Document and by referring to other relevant documents and literature, the authors use critical social theory to develop an 
understanding of the consequences of the inferences in this policy document for children and families. There is also an alignment with the work of Bowe, Ball and Gold (1992) by considering the idea that all policy includes certain assumptions, omissions and contradictions, which work to produce both intended and unintended consequences for the individuals, at which the policy is directed.

The authors take the view that childhood development is a problematic. This notion will be addressed through an analysis of policy discourses about healthy childhood development within the Strategy Document. This will involve undertaking a discursive analysis of the terms affiliated with childhood development within the Strategy Document including, "healthy”, "at-risk” and "productivity”. Such analysis requires an identification of inconsistencies surrounding childhood development within the Strategy Document, particularly in relation to the paradox of progress (COAG, 2009; Stanley, 2003; Stanley, Richardson, \& Prior, 2005).

There is an argument that the Strategy Document equates healthy childhood development with a set of outcomes including attainment of education, employment and future productivity and, in doing so, creates the idea of proper childhood development. Reforms within the Strategy Document can be recognised as a form of intervention on groups who are 'at-risk' of improper development, specifically, groups who are not able to function productively and support their own and the nation's economic goals. This perspective validates certain traits and marginalises others producing judgements about what represents 'the right thing'.

The vision of early childhood development as outlined within the Investing in the Early Years document suggests that, "by 2020 all children will have the best start in life to create a better future for themselves and for the nation” (COAG, 2009, p. 13). 
This vision is maintained by a set of policy objectives, which work towards, “...greater social inclusion; improved outcomes for the majority of children specifically Indigenous children and the most disadvantaged; and increased productivity and international competitiveness" (COAG, 2009, p. 13). Within the document, positive early childhood development outcomes include “... improved health, cognitive and social development leading to improved transition to school and improved educational, employment, health and wellbeing outcomes” (COAG, 2009, p. 4). A set of "key elements” (COAG, 2009, p. 16) are recognised as important for an "effective childhood development system" (COAG, 2009, p. 16) that meets early childhood development goals, and includes, "support for children, parents, carers and communities; responsive early childhood development services; governance and funding; quality and regulation; knowledge management and innovation; workforce and leadership development; and infrastructure” (COAG, 2009, p. 16).

While none of these suggestions appear unreasonable and, in fact, look very attractive, it is the idea that there might be judgement about child development that

prompts some concern. Terms such as 'best', 'better' and 'effective' suggest that there are ways to measure such notions and that development goals are set to according to these determined measures. It is how such measures are determined and how particular understandings are categorised, which should be open to investigation. Moreover, the idea that policy can be implemented in ways that categorise what is best or better can also prove to be problematic.

\section{Searching for "Better"}

In most cases, the main focus of most policy reform tends to be in the search for something better and the Strategy Document is no exception. In and of itself, the idea of 
searching for something better appears to be a reasonable one. For example, why would anyone in the community not want the best start in life (COAG, 2009) for children? However, it is not the sentiment in the documents but the consequences these sentiments produce, which tend to be problematic. Thus, when focussing on policy that is seeking to produce better outcomes, it is important that a precise examination of the consequences is considered. Such an examination is not meant to situate policy as right or wrong. Rather, this work intends to understand policy reform as always problematic and so needing to be opened up for scrutiny (Bowe, Ball, \& Gold, 1992).

An example of such issues has been highlighted by the seminal work of Deborah Tyler (1993). While not focussing specifically on policy, Tyler highlights the consequences of scrutinising children and families in the search for better outcomes. Tyler uses a historical analysis of child development literature to demonstrate how a certain type of citizen can be produced and examines the mechanisms used to work towards such an outcome. Tyler argues that child development literature has gradually promoted the virtues of the kindergarten as a mechanism for directing children toward rationality, autonomy and self-regulation (Author's Own, 2006). This assisted in enabling a teacher to direct the child towards social desirability. Tyler (1993) states:

Alongside rationality, the better child would move steadily toward total independence by taking every opportunity to exercise greater control and autonomy. For the child to be moving towards independence also meant taking responsibility for one's self and one’s actions, and discovering that the desire to do something was not sufficient reason for doing it. But the child who was forced into obedience would never discover 'inner discipline' and would come only to resent the rules, and not regulate the 
self. The child was capable of self-regulation, and to realise its full potential must develop this capacity (p. 44).

Tyler's argument is that the organisation of space in the kindergarten worked in ways to increase surveillance of children and maintain the capacity for self-regulation (Author's Own, 2006). She suggests that certain non-coercive techniques were used to achieve this and that these became part of the practices within these kindergarten organisations (Author’s Own, 2006).

Tyler's work centres on the establishment and function of the Lady Gowrie Child Centres in Australia, which were built as model kindergartens during World War Two (Author's Own, 2006). The newly established National Health and Research Council had strongly lobbied the Commonwealth Government for their introduction and, as a result, these centres were funded by the Commonwealth Department of Health and not by educational bodies (Author's Own, 2006). According to Tyler (1993),

The Lady Gowrie Centres were 'special purpose’ structures in that their function was the training of two to six year olds as one part of a range of strategies aimed at shaping and maximising the capacities of the population to meet national goals (p. 45).

Tyler also argues that Lady Gowrie centres were "special purpose” in that they were used to promote particular socially acceptable behaviours in the child of a type that child psychologists held as important (Author's Own, 2006). These centres, which were examples of excellence in early childhood education and care, were used as observation centres for both staff and prospective students. The children in these centres became objects of surveillance by being subjected to the normalising gaze, as the object of observation and evaluation by outside organisations (Author's Own, 2006). This 
ensured the constitution of a certain type of child, whose behaviour was regulated by the organisation of space, the values of the teacher and the image of the child as hope for the future (Author's Own, 2006).

The Lady Gowrie centres, exist today and still hold reputations as quality early childhood education and care centres within the early childhood community (Author's Own, 2006). The surveillance, normalisation and individualisation of young children are examples of how non-coercive techniques can be used to create a certain type of citizen (Rose, 1999, 2000). Tyler's work acts as an example of how populations can be governed by normalising particular behaviours, thereby creating a regime of truth (Foucault, 1980) producing what is or is not unruly behaviour in any given situation (Author's Own, 2006). If individuals or groups of individuals are continually subjected to techniques of surveillance, then unruly behaviour is made more visible (Author's Own, 2006).

Tyler's work is relevant here because it helps in the development of an understanding of how discourses work to produce better behaviour and self-regulation. As Foucault (1980) attests discourses are systems of language use and, at the same time, systems of power relations. This means that discourse works to produce understandings of propriety, which work as technologies of governance to encourage individuals to self-regulate to meet normalised understandings of 'proper' behaviour. What is also significant about this work is that it makes it possible to see that policy works in a similar way in its search for something better. Policy produces particular understandings of truth by normalising certain behaviours. It is with such ideas in mind that the examination of the afore-mentioned policy document proceeds. 


\section{Strategy Document, Childhood Development and Outcomes: Alignment of National and Individual Goals}

As previously stated, the Strategy Document proposes a set of guidelines, procedures and goals to ensure “... that by 2020 all children have the best start in life to create a better future for themselves and for the nation” (COAG, 2009, p. 4). The document is produced out of an understanding that development during the early years is crucial to the future of an individual's life (Mustard, 2001), and is determined through a combination of genetics and experiences throughout childhood (COAG, 2009). A benchmark for a 'better future', involves an identification of a set of outcomes, which can be categorised as 'healthy' or proper childhood development. The document states “... improved health, cognitive and social development [lead] to improved transition to school and improved educational, employment, health and wellbeing outcomes" (COAG, 2009, p. 4). The Strategy also clarifies that investing towards these outcomes is “cost-effective” and works towards the individuals’ and nation’s economic goals, and further ensures competitiveness in the global economy (COAG, 2009, p. 6).

The inference in these statements is that both individual and national goals are aligned. Such an idea espouses the notion that there is harmony between the goals of the nation and the goals of the individual. This idea is vital to notions of propriety, as policy reform that seeks to provide the "best start in life” requires that individuals behave in ways that affirm this notion. This means that individuals must self regulate to align with ideas that produce this policy's idea of a best start. In short, individuals should become responsibilised.

Borrowing from Nikolas Rose (2000, p. 1395), the term responsibilisation “asserts our belief in a common purpose”. This term has become the means by which 
particular values, beliefs and ethics are promoted to the population as desirable qualities (Author's Own, 2006). Rose (2000, p. 1396) states that as people need a "framework of belief”, this method of governance (Rose, 2000, p. 1397) promotes mutual responsibility and reciprocal obligation as the crucial to civil societies (Author's Own, 2006). Consequently, the civic-minded citizen self regulates and becomes responsibilised, that is, comes to understand this process as the proper way to function (Rose, 2000). Moreover, the focus on a belief in a common purpose produces responsibilised communities, which include autonomised individuals who derive guidelines and techniques from these communities to enable them to "enact their freedom” (Rose, 2000, p. 1399). It is through this process that individuals are subjected to technologies of government (Rose, 1999), thereby becoming agents in particular and desirable ways (Author’s Own, 2006).

Heeding Rose’s ideas here allows a different view of notions such as "best” and "better". What these ideas emphasise is the notion that particular understandings of best and better are at play here. What individuals must do is follow these particular understandings and exist in harmony with them in order for their best start in life to be achieved. In terms of child development and progress, this means that children must develop properly according to normalised understandings and that parents must do all that they can to enable this proper development.

Thomas Popkewitz (2003) builds on Rose’s notion of “responsibilisation” in his work. He asserts that, in the USA, the notion of a community is central to the notion of progress of both schooling and nation (Author's Own, 2006). As Popkewitz (2003) understands it, “The metaphor of community is evoked in the US reforms of site-based 
management, home-school collaboration and curriculum discussions of the classroom as a “community of learning” (p. 50).

Popkewitz (2003) argues the importance of the notion of community in bringing together "multiple salvation themes of progress", coming as it does with a "universal value of goodness" (p. 50). This allows the possibility of re-locating 'community' within a field of practices that join the 'life-long learner' with what he terms "the pedagogicalisation of the parent” (Popkewitz, 2003, p. 50). The main idea then is the usefulness of developing "partnerships" between the school and the home, which become characterised as friends not enemies of diversity (Author's Own, 2006). However, Popkewitz indicates that while new emphasis is placed on diversity and equity, difference continues to be maintained by producing new sets of distinctions and differences that exclude particular categories of families, placing them outside what normally indicates success (Author’s Own, 2006).

While Popkewitz's ideas are particularly related to schooling in the US, they are still able to inform the discussion here. What Popkewitz is saying is that the idea of a nation's progress is linked to the notion of responsibilised communities where partnerships between individuals and government are forged for the "good of the nation”. Such partnerships require that individuals receive the best start in life to ensure their proper development as ethical citizens who can contribute to economic prosperity and do not become a "drain” on the community.

\section{Outlining 'at-risk' groups, lacking resources as excluded from proper development}

Again in many ways such an idea appears reasonable. However, problems occur when parents are unable to contribute to this idea of progress for a variety of reasons. 
Placing emphasis on economic productivity of individuals to further a nation's goals blames the individual and disregards historical circumstances, which have perpetuated social inequalities. According to Bourdieu (1984, 2001), individuals engage in social and systemic practice like players in a game and will try to adhere to the rules of the game (Author's Own, 2006). Moreover, Bourdieu (1984, 2001) states that for individuals to participate successfully in the game of social engagement, they must possess particular forms of capital, namely economic, social and cultural capital. Such a view highlights the fact that if these rules of the game are beyond the reach of particular individuals, for example, when individuals are part of disadvantaged families, then the economic, cultural or social contexts of these families might well prevent them from being able to reach normalised understandings of proper development. It is unlikely that the social and systemic conditions, which produce these inequalities will be scrutinised appropriately. Therefore, the individual families will be held accountable regardless of context. The imbalances in the systems that hamper this process such as, unequal access to wealth and resources will not necessarily be addressed.

This emphasis on economic productivity also situates families and children outside of healthy development, and has various results on those labelled at-risk. As clarified by Author's Own (2010), in this instance the consequences of labelling children and families at risk produces them as cases for intervention and works to further differentiate them as their development is no longer congruent with policy ideals. Such notions are demonstrated in the Strategy Document as it highlights groups that are at risk regardless of their capital and singles them out for intervention. Through the exemplification of “...jobless families, [some] Indigenous children, and children involved in the protection system or out-of-home care" (COAG, 2009, p. 10) as "high- 
risk" or "areas of concern" (COAG, 2009, p. 10), the Strategy Document supports the ideas presented by Bourdieu (1984) and outlines groups currently excluded from successful performance. Furthermore, Investing in the Early Years is explicit in its identification of Aboriginal children as a group for concern. The "at risk" status of Aboriginal children is illustrated through the use of a table ranking Aboriginal and Australian children against children from OECD nations across a variety of health and wellbeing indicators including, literacy and numeracy levels, mental health, teenage pregnancy and birth rate. Children are considered at-risk and excluded from success when their families find their "roles and responsibilities" (COAG, 2009, p. 7) as outlined within Investing in the Early Years unattainable, specifically do not meet a single or multiples of their requirements, and are unable to, “... provide a nurturing home environment and to access the services and supports to best meet a child's developmental needs...” (COAG, 2009, p. 7). Thus, the performance of both parents and children is held up for scrutiny and judged according to particular understandings of propriety. Parents are situated as cases for intervention and are therefore, excluded from successful categories. The consequences of such exclusion are that families who are already under pressure come under further pressure, making successful performance more difficult to attain.

\section{Interventions, surveillance and technologies of governance}

In policy documents such as Investing in the Early Years, outcomes can only be achieved through the implementation of a set of reforms concerning childhood education, care, wellbeing and health. These reforms aim to ensure that both families and children are supported, to allow for positive outcomes for children, and current and future workforce participation (COAG, 2009, p. 6). The proposed benefits are said to 
move beyond families and children and result in “... [enhanced] human capital and capability, increased productivity, greater social inclusion and reduced public expenditure in health, welfare and crime related to disadvantage over the life course" (COAG, 2009, p. 6). The Strategy Document also clarifies, if these outcomes are not met, and reforms ineffective, children will have 'poor' development and this impacts the nation through, “...increased social inequality, reduced productivity and high costs associated with entrenched intergenerational disadvantage” (COAG, 2009, p. 6).

In the Australian culture, such statements indicate a strong focus on performativity (Author's Own, 2010; Ball, 2003, 2004), which is having very real organising effects for children and families (Author's Own, 2010). These organising effects are produced by what is believed to be true about success and propriety. Documents such as Investing in the Early Years can either intentionally or unintentionally contribute to particular notions of performativity via the rhetoric used and also via the understandings that rhetoric produces. This analysis demonstrates that adherence to imperative discourses, even at a micro level, can produce multiple effects that can be highly problematic (Author’s Own, 2010). As Rose (1990), states, childhood is the most governed of all categories and thus, as children and, by association, their families, engage in and become objects of hyper-surveillance and techniques of governmentality, then the importance of "being included as proper" becomes inextricably linked to their performance as ethically responsibilised citizens. Viewed in this way, the desire to perform according to notions of propriety causes parents and children to adhere to imperative discourses and thus, move from "domination to domination” (Foucault, 1984, p. 85) in order to be included (Author’s Own, 2010). 
Investing in the Early Years claims that the inclusion of children, and, by affiliation, their parents along the road to proper development will be facilitated by a set of “reform opportunities” (COAG, 2009, p. 5). These reform opportunities can be seen as mechanisms of surveillance and tools of government as many of them focus and intervene with groups at-risk (Rose, 1990), target both children and families and include but are not limited to, the National Family Support Program, National Partnership Agreement on Early Childhood Education, National Partnership Agreement on Preventative Health, and a national set of 'standards' and a 'rating system' for childhood education and care (COAG, 2009, p. 5). Furthermore, these reforms go to support the stated link between 'responsibilisation' and 'pedagogicalisation' (Author's Own, 2006). By including education and a national set of educational standards within reforms, education becomes a means to encourage children to reach the level of responsibilisation and proper development, and to be economically competitive in a globalised world.

The knowledge and importance of childhood development evident within the Strategy Document is valid and the paper does not dispute the importance of development during the early years on the future of a child's health and wellbeing. However, the authors do take the view that the affiliation of healthy child development with individual productivity and national economic goals in a global economy is problematic. As O’Leary (2010) suggests sometimes such interventions contain elements of social control “...creating traps within the prevailing social conditions” (p. 10). While such interventions can be viewed as a way to offer hope to disadvantaged communities, when linked with economic productivity, they can also be viewed as a 
means of controlling unruly sections of the community (Popkewitz, 2008). In Popkewitz’s (2008, p. 4) terms, such interventions:

...[entail] comparative installations that differentiate and divide those who are enlightened and civilized from those who do not have those qualities - the backward, the savage and the barbarian of the $19^{\text {th }}$ century and the at risk and delinquent child of the present. The universal and inclusive practices of ... reforms that speak about inclusion locate difference and incomplete elements, points and directions in the process of inclusion and exclusion. ...[R]eforms....are to provide an inclusive society where 'all children learn' and there is 'no child left behind'. The gesture is to make all children the same and on equal footing... [where] ...hope overlaps with fears of the child whose characteristics are a threat to moral unity.

Thus, children and families who do not meet normalised understandings of healthy or proper development are excluded from categories that signify successful performance as ethical citizens.

\section{The 'Paradox of Progress'}

The 'paradox of progress' is understood by the fact that as the nation's wealth increases, there is also increasing social inequality (Stanley, 2003; Stanley, Richardson, \& Prior, 2005). In Australia it is illustrated as the increase in health disparities between those with and without wealth, including birth weight and infant mortality despite economic growth (Stanley, 2003; Stanley, Richardson, \& Prior, 2005). The Strategy Document, which regards early childhood development and childhood health and wellbeing as mechanisms to ensure a productive workforce, is problematic when the 
paradox of progress is taken into account. Considering that the wealthiest nations, nations with high Gross Domestic Product (GDP), have higher social inequalities than those who are less wealthy (Stanley, 2003), it is clear that economic progress is not a means to ensure health and wellbeing and reduce social inequalities within the nation. Consequently, the Strategy Document's aims to ensure economic development and workforce productivity may result in greater social inequalities.

A part of the problem resides in productivity measures, and what is regarded as the 'wealth' or 'growth' of the nation. The wealth of a nation is generally understood from a nation's GDP and their economic growth regarded as their increase in GDP (Constanza et al., 2009) after adjusting for inflation. Its use as a measure is meant to present the value of goods and services produced within a country and not to be a measure of the country's wellbeing (Constanza et al., 2009). With this understanding, encouraging an increase in productivity through sound early childhood development will result in just that, an increase in productivity but not necessarily a reduction of inequalities or wellbeing for current and future generations.

Encouraging this increase in productivity also leads to issues around performativity (Ball, 2012), which produces its own consequences. Such consequences are highlighted by Ball (2012) who argues that neoliberalism uses performativity as a policy technology, where performance and productivity at all levels "must be constantly audited so it can be enhanced’ (p. 12). Ball (2003) attests, that performativity:

[I]s a technology, a culture and mode of regulation that employs judgements, comparisons and displays a means of incentive, control, attrition and change - based on rewards and sanctions (both material and symbolic). The performances (of individual 
subjects or organisations)...encapsulate or represent the worth, quality or value of an individual or organisation within a field of judgement. The issue of who controls the field of judgement is crucial (p. 216).

The notion of performativity relates to the document as it highlights what healthy development looks like, stating that all families need to reach this normalised understanding of development so that the nation can prosper. Performativity works to produce an understanding of the necessary levels of citizenry to which individuals should strive. There is an inference that a certain level of performativity from parents and children is necessary so that proper child development can occur, leading to successful citizenry for both the families and for the Australian community.

However, such levels of performativity have their own consequences for the children and families who seek to reach these suggested levels. Meadmore and McWilliam (2001) point to the consequences of performativity stating that:

....as a practice and as a fabrication [it] can contribute to the deterioration of ...communities who invest in its truth claims... To pretend that outcomes will necessarily be equitable if everyone lifts their game in terms of performance is to deny the diversity of Australian education (p. 42).

The issue of performativity is an important one in terms of developing an understanding of the position of families who do not have the necessary capital to attain particular levels of performance. If parents want to be viewed as 'good' or 'excellent”, then they must perform well when caring for their children. Parents, particularly mothers, tend to view parenting as a rewarding and highly responsible undertaking (Jenks, 1996a). To 
exist as improper infers failure at one of the most important responsibilities in life. An individual who abuses or neglects a child is viewed, in western societies, as particularly deviant. Improper parents, while not being categorised in the same way as abusers, are nonetheless determined to be failures in significant terms (Author's Own, 2006). As Jenks (1996a, 1996b) states, the present postmodern conceptualisation of childhood as "nostalgia" (1996a, p. 15) heightens emotions that exist in relation to the care of children acting to position them as 'vulnerable' and at risk (McWilliam, 2003). Thus, parents who exploit this vulnerability by not performing properly in particular parenting roles are definitely situated problematically (Author’s Own, 2006).

Another consequence of the focus on performativity is the possibility of "parent fatigue”. Author's Own (2006) coined this term to describe what happens for parents who are constantly trying to reach particular levels of performance when engaging in the child's schooling. The anxiety that might result in such a process can be very debilitating and can lead to parents trying too hard sometimes for little result.

Parent fatigue may best be understood by examining the concept in terms of the work of Bourdieu (1984, 2001). Bourdieu's concept of habitus contributes to the development of an understanding of how parents undertake their role in social and systemic practice. This concept can also assist in explaining the existence of parent fatigue (Author's Own, 2006). As habitus is the unconscious internalisation of particular dispositions, schemas, know-how and competence that determines how individuals engage in social practice (Bourdieu, 1984), the production of an individual's habitus can be impacted on by particular prominent discursively produced regimes of truth. An individual's performance in games of social practice is determined by the particular regimes of truth that produce propriety in terms of such practice. Consequently, high 
levels of performativity can signify the characteristics that contribute to individual's understanding or comprehension of their categorisation as a proper and interested parent who performs ‘successfully’. Thus, parent fatigue becomes a more likely possibility, when an individual internalises the propriety of such high level performance as an important determinant of 'success” in the parenting game (Author's Own, 2006).

What can be learned then is that policy documents like the Strategy Document examined in this paper, seek to assist in the provision of better outcomes for children and families, which leads to better outcomes for the community as a whole. However, what is often misrecognised in such a process is that the search for better requires high levels of performance from children and parents when these notions of better are linked to economic prosperity. The assumptions, omissions and contradictions, which are always a part of such policy reform, work to produce particular understandings of responsibilised citizens who join wholeheartedly in the search for better for the economic good of the nation. Failure to join in this idea of progress for whatever reason, leads to parents and children being viewed as improper and refuses them admittance to the categories of ethical citizen. Such a process is particularly problematic for groups already considered at risk, as it further adds to their exclusion from successful categories of performance in social practice. Moreover with these groups, performativity may be a continuous cycle, where their perfomativity in health statistics has resulted in an at-risk and "cause for intervention” label and if failing to progress or perform in the future, an amplification of this at-risk and 'cause for intervention' categorisation. 


\section{Conclusion}

This paper has highlighted how childhood development and at-risk groups are understood in their relation to the concepts of economic growth and individual and national productivity in the Investing in the Early Years Strategy Document. The paper has argued that this document attributes healthy and proper childhood development with economic productivity and national goals, and in doing so, may be working towards the responsibilisation (Popkewitz, 2003; Rose, 2000) of individuals and consequences (Rose, 1990) for at-risk groups who are unable to adhere to responsibilisation and performance standards. Drawing from Ball (2012), Author's Own (2006), and Meadmore and McWilliam (2001), the paper also acknowledged the consequences of performativity when aligned with productivity for children and their families.

The representation of proper child development as understood within the Investing in the Early Years Strategy Document has the potential to further encourage social inequalities and health disparities it aims to remedy, when the 'paradox of progress' is understood as a contributing factor. Inconsistencies surrounding current policy aims and directions and consequences resulting from current understandings of childhood development and its link to individual and national productivity, are important for further policy development, which should not work to subjugate children and families. 


\section{References}

Author's Own (2006).

Author’s Own (2010).

Ball, S.J. (2003). The teacher's soul and the terrors of performativity, Journal of Educational Policy, 18(2), 215-228. DOI: 10.1080/0268093022000043065

Ball, S.J. (2004). Performativity, privatisation and the post-welfare state, Finnish Journal of Education, 35(1), 6-20.

Ball, S.J. (2012). The making of a neoliberal academic, Research in Secondary Teacher Education, 2(1), 29-31.

Bourdieu, P. (1984). Distinction: A Social Critique of the Judgment of Taste. Cambridge, Massachusetts: Harvard University Press.

Bourdieu, P. (2001). The Forms of Capital, in M. Granovetter \& R. Swedberg (Eds.) The Sociology of Economic Life (2nd ed.). Oxford: Westview Press.

Bowe, R., Ball, S.J. \& Gold, A. (1992). Reforming Education and Changing Schools: Case Studies in Policy Sociology. London: Routledge.

Constanza, R., Hart, M., Posner, S. \& Talberth, J. (2009). Beyond GDP: The Need for New Measures of Progress. Available from:

http://dr.archives.pdx.edu/xmlui/bitstream/handle/psu/8349/Costanza_BeyondG DP.pdf?sequence $=1$

Council of Australian Governments [COAG]. (2009). Investing in the Early Years - A National Early Childhood Development Strategy. Available from: http://www.coag.gov.au/node/205 
Foucault, M. (1980). Truth and Power, in C. Gordon (Ed.) Power/Knowledge: Selected Interviews and Other Writings, 1972-77. New York: Pantheon Books.

Foucault, M. (1984). Polemics, Politics and Problematisations, in P. Rabinow (Ed.) Michel Foucault, Ethics: Essential Works of Foucault 1954-1984 (vol. 1). London: Penguin Press.

Heckman, J. (2006). Skill formation and the economics of investing in disadvantaged children, Science, 312(5782), 900-902. DOI: 10.1126/science.1128898

Jenks, C. (1996a). The Postmodern Child, in J. Brannen \& M. O’Brien (Eds.) Children in Families: Research and Policy. London: Falmer Press.

Jenks, C. (1996b). Childhood. London: Routledge.

McWilliam, E. (2003). The vulnerable child as a pedagogical subject of risk management, Journal of Curriculum Theorising, 19(2), 35-44.

Meadmore, D. \& McWilliam, E. (2001). The corporate curriculum: Schools as sites of new knowledge production, Australian Educational Researcher, 28(1), 31-45. DOI: $10.1007 / \mathrm{BF} 03219743$

Mustard, J. (2001). Early Childhood Development and the Brain - The Base for Health, Learning and Behaviour through Life, in M.E. Young (Ed.) Investing in Our Children's Future: From Early Child Development to Human Development. Washington, District of Columbia: World Bank.

O'Leary, P. (2010). Hope, Social Intervention and the Future, in S. Robb, P. O’Leary, A. Mackinnon \& P. Bishop (Eds.) Hope: The Everyday and Imaginary Life of Young People on the Margins. South Australia, Australia: Wakefield Press. 
Popkewitz, T.S. (2003). Governing the Child and Pedagogicalization of the Parent, in M. Bloch, K. Holmlund, I. Moqvist \& T. Popkewitz (Eds.) Governing Children, Families and Education: Restructuring the Welfare State. New York: Palgrave Macmillan.

Popkewitz, T.S. (2008). Cosmopolitanism and the Age of School Reform: Science, Education and Making Society by Making the Child. New York, NY: Routledge. Rose, N. (1990). Governing the Soul: The Shaping of the Private Self. New York: Routledge.

Rose, N. (1999). Powers of Freedom: Reframing Political Thought. Cambridge, UK: University Press.

Rose, N. (2000). Community, citizenship and the third way, American Behavioural Scientist, 43(9), 1395-1411.

Stanley, F. (2003). The real brain drain—Why putting children first is so important for Australia. Newsletter of the Australian Cerebral Palsy Association (vol. 8, issue 2). Available from: http://www.docstoc.com/docs/29187980/The-Real-BrainDrain---Why-putting-children-first-is-so-important

Stanley, F., Richardson, S. \& Prior, M. (2005). Children of the Lucky Country? Sydney, Australia: Macmillan.

Tyler, D. (1993). Making Better Children, in D. Meredyth \& D. Tyler (Ed.) Child and Citizen: Genealogies of Schooling and Subjectivity. Brisbane, Queensland: Institute for Cultural and Policy Studies, Griffith University. 